\title{
ANALISIS GAYA BAHASA DALAM NOVEL SEBUAH USAHA MELUPAKAN KARYA BOY CANDRA
}

\author{
Kurniawan Basara ${ }^{1}$, Sri Suryana Dinar ${ }^{2}$, dan Hilaluddin Hanafi ${ }^{3}$ \\ pbsi.fkip.uho@gmail.com \\ 1,2,3, JurusanPendidikanBahasadanSastra Indonesia, \\ FakultasKeguruandanIlmuPendidikan, UniversitasHalu Oleo \\ KampusHijauBumiTridharmaAnduonohu, Kendari, Indonesia
}

\begin{abstract}
Abstrak
Penelitian ini menelaah gaya bahasa dalam novelSebuah Usaha Melupakan karya Boy Candra. Novel adalah sebuah karya sastra yang medianya adalah bahasa. bahasa merupakan alat pendukung yang sangat penting bagi pengarang. Setiap pengarang tidak sama dalam memanfaaatkan khazana bahasa dalam karyanya karena bahasa untuk mengembangkan cerita agar dapat menarik perhatian pembaca cerita yang kompleks tidak mesti disuguhkan pula dengan bahasa yang kompleks, namun cerita yang kompleks dapat dibuat menjadi menarik dengan memanfaatkan bahasa sebaik mungkin didalam karya satra itu khususnya novel. Gaya bahasa yang digunakan oleh pengarang sesuai dengan kecakapan pengarang dalam memainkan bahasa dalam penyampaian ceritanya apakah disampaikan secara kompleks maksudnya mudah dipahami oleh pembaca dengan sekali baca pembaca sudah tahu apa ceritanya, ataukah pengarang menggunakan bahasa analogi atau kiasan. Sehingga untuk memahami cerita pembaca harus pulaberimajinasi seperti halnya novel-novel karya Boy Candra. Rumusan masalah dalam penelitian ini adalah:gaya bahasa apa sajakah yang digunakan yang digunakan dalam novel Sebuah Usaha Melupakan karya Boy Candra?. Tujuan penelitian ini adalahuntuk mendeskripsikan dan menganalisis tentang gaya bahasa dalam novel Sebuah Usaha Melupakan karya Boy Candra. Penelitian ini merupakan penelitian deskriptif kualitatif. Sumber data yang digunakan dalam penelitian ini adalah novel Sebuah Usaha Melupakan karya Boy Candra. Teknik pengumpulan data menggunakan teknik baca catat. Teknik analisis menggunakan pendekatan srtuktural. Hasil analisis menunjukkan bahwa ada empat jenis gaya bahasa perbandingan yaitu : (1) gaya bahasa metafora, (2) gaya bahasa personifikasi, (3) gaya bahasa dipersonifikasi (4) gaya bahasa antitesis. Kemudian gaya bahasa pertentangan menunjukan adanya satu jenisgaya bahasa yaitu gaya bahasa hiperbola.
\end{abstract}

Kata Kunci : analisis, gaya bahasa, novel 


\begin{abstract}
This research examines the language style in Boy Candra's novel An Usaha Forgetting. A novel is a literary work whose medium is language. language is a very important support tool for authors. Every author is not the same in utilizing the treasures of language in his work because language to develop stories in order to attract the attention of readers of complex stories does not have to be presented with complex language, but complex stories can be made interesting by utilizing the best possible language in the works of literature especially. novel. The language style used by the author is in accordance with the author's skill in playing the language in the delivery of the story, whether it is conveyed in a complex manner, the meaning is that it is easy to understand by the reader. With one reading, the reader already knows what the story is, or does the author use analogical or figurative language. So that to understand the story, the reader must also imagine like the novels by Boy Candra. The formulation of the problem in this study are: what language styles are used in Boy Candra's novel An Usaha Forgetting?. The purpose of this study is to describe and analyze the style of language in Boy Candra's novel An Effort to Forget. This research is a qualitative descriptive study. The data source used in this research is Boy Candra's novel An Usaha Forgetting. The data collection technique used the reading note technique. The analysis technique uses a structural approach. The results of the analysis show that there are four types of comparative language styles, namely: (1) metaphorical language style, (2) personified language style, (3) personified language style (4) antithesis language style. Then the disagreement language style shows that there is one type of language style, namely hyperbole language style.
\end{abstract}

\title{
Keywords: analysis, language style, novel
}

205| Jurnal BASTRA (BahasadanSastra), Vol. 5 No.2, Edisi April 2020/e-ISSN: 25033875 /http://ojs.ohu.ac.id/index.php/BAS 


\section{PENDAHULUAN}

Manusia merupakan makhluk yang memiliki ketertarikan terhadap keindahan,sifat dasar yang melekat pada manusia adalah kompleksitas, didalam kompleksitasnya manusia tumbuh dan hidup bersama dengan disertai cerita dan wacana apapun yang dialaminya akan dihadikan sebagai cerita baik itu berupa obrolan maupun tulisan. Beberapa kejadian yang dialami manusia terkadang memicu sifat kreatifitasnya tumbuh dalam hal ini obrolan- obrolan maupun tulisan berdasarkan pengalaman yang dialami itu, kemudian disusun menjadi sebuah cerita. Berbagai pengalaman ditangkap dan dituliskanmenjadisebuah kisah yang menghadirkan ketertariakan dan minat untuk dibaca dan didengarkan. Maka hadirlah karya sastra sebagai salah satu contoh dari hasil kreatifitas yang ditulis berdasarkan pengalaman manusia tersebut. Beberapa contoh sastra yang populer dan banyak diminati dalam hal ini sastra tulisan,ialah puisi dan novel.

Untuk mengembangkan cerita Berdasarkan pengamatan setelah membaca novel Sebuah Usaha Melupakan banyak kalimat-kalimat yang akan sulit ditafsirkan maknanya sehingga pembaca merasa kesulitan menangkap pesan yang disampaikan pengarang atas dasar itulah, dilakukan telaah terhadap gaya bahasa. Pada mulanya karya sastra memang untuk dinikmati keindahanya bukan untuk dipahami. Akan tetapi, mengingat bahwa karya sastra juga merupakan sebuah produk budaya, maka persoalanya menjadi lain. Karya sastra berkembang sesuai dengan proses kearifan zaman sehingga lama-kelaman sastra pun berkembang fungsinya, yang semula hanya sekedar menghibur, namun pada tahapan proses berikutnya karya sastra juga dituntut untuk dapat memberikan suatu yang berguna bagi pembaca hal ini relevan dengan idiom sastra "Dulce et Utile" (menyenangkan dan berguna) oleh karena itu, peneliti tertarik menganalisis novel sebuah usaha melupakan dari segi gaya bahasa. Alasan peneliti menggunakan istilah gaya bahasa lebih mudah ditafsirkan oleh pembaca dan pembagian gaya bahasa lebih luas dari pada majas yang lebih sedikit pembagian jenis-jenisnya. Peneliti memilih gaya bahasa dalam novel Sebuah Usaha Melupakan untuk diteliti dan dianalisis karena dalam novel ini, berdasarkan hasil telaah awal peneliti menunjukan adanya berbagai gaya bahasa yang digunakan penulis didalam menceritakan sebuah novel tersebut terutama jenis gaya bahasa perbandingan dan pertentangan. Setelah membaca novel Sebuah Usaha Melupakan, peneliti banyak menemukan gaya bahasa yang digunakan pengarang dalam menyampaikan setiap gagasanya untuk membuat isi cerita lebih menarik. Sedangkan alasan peneliti memilih novel Sebuah Usaha Melupakan karya Boy Candra sebagai objek penelitian sebab peneliti tertarik dengan jalan cerita yang disuguhkan pengarang, yang menceritakan tentang kisah seorang laki-laki yang sangat mencintai pasangannya yang ditinggalkan karna orang ketiga dan semula tidak memiliki semangat untuk hidup dan kemudian dia berjuang dan bangkit dari keterpurukannya untuk menyembuhkan lukanya dengan jatuh cinta kembali.

Agar dapat menarik perhatian pembaca cerita yang kompleks tidak mesti disuguhkan pula dengan bahasa yang kompleks, namun cerita yang kompleks dapat dibuat menjadi menarik dengan memanfaatkan bahasa sebaik mungkin didalam karya satra itu khususnya novel. Gaya bahasa yang 
digunakan oleh pengarang sesuai dengan kecakapan pengarang dalam memainkan bahasa dalam penyampaian ceritanya apakah disampaikan secara kompleks maksudnya mudah dipahami oleh pembaca dengan sekali baca pembaca sudah tahu apa ceritanya, ataukah pengarang menggunakan bahasa analogi atau kiasan. Sehingga untuk memahami cerita pembaca harus pulaberimajinasi seperti halnya novelnovel karya Boy Candra. Boy Candra adalah seorang pengarang mempunyai kepandain mengisahkan cerita dengan bahasa-bahasanya yang indah yang menarik hati pembaca untuk membaca novelnya.

Berdasarkan uraian latar belakang yang telah dipaparkan maka yang menjadi masalah dalam penelitian ini adalah bagaimanakah gaya bahasa yang digunakan dalam novel Sebuah Usaha Melupakan karya Boy Candra?

Tujuan penelitian ini adalah untuk mendeskripsikan dan menganalisis tentang gaya bahasa dalam novel Sebuah Usaha Melupkan karya Boy Candra.

Tujuan penelitian ini adalah :

a. Sumbangan pemikiran dalam upaya meningkatkan mutu apresiasi terhadap karya sastra, khususnya mengenai gaya bahasa dalam novel indonesia modern.

b. Bahan masukan dalam pengembangan apresiasi sastra indonesia baik dunia pendidikan pada khususnya maupun dikalangan masyarakat pada umumnya.

c. Sumbangan pemikiran tentang kajian gaya bahasa dalam novel bagi para peneliti yang relevan.

\section{METODE DAN TEKNIK PENELITIAN}

Jenis penelitian yang digunakan dalam penelitian ini adalah penelitian kepustakaan (Libary Research). Dikatakan kajian kepustakaan karena kajian dalam penelitian ini berupa data tertulis dan kegiatan dalam menncari, mengumpulkan, dan mendapatkan data-data yang diperlukan dengan cara menelaah dan menganalisis penggunaan gaya bahasa dalam novel Sebuah Usaha Melupakan karya Boy Candra.

Metode yang digunakandalampenelitianiniadalahmet odedeskriptifkualitatif.Metodedeskriptif ialahpenelitian yang dimaksudkanuntukmengumpulkaninfor masimengenaisubjekpenelitian.

Data yang digunakan dalam penelitian ini adalah data tertulis berupa teks novel yang memuat gaya bahasa dalam novel Sebuah Usaha Melupakan karya Boy Candra.

Sumber data penelitian ini adalah sumber data tertulis dalam novel Sebuah Usaha Melupakan yang diterbitkan oleh penerbit Mediakita Jakarta cetakan pertama 2016 dan terdiri dari 305 halaman.

Teknik pengumpulan data dilakukan dengan cara sebagai berikut:

1. Teknik baca, yakni membaca secara analisisnovel dalam novel Sebuah Usaha Melupakan karya Boy Candra.

2. Teknik catat, yakni mencatat datadata tentang gaya bahasa yang terdapat dalam novel Sebuah Usaha Melupakan karya Boy Candra.

Analisis data dalam penelitian ini menggunakan pendekatan objektif. Pendekatan nobjektif yaitu suatu pendekatan yang digunakan dalam rangka mengkaji unsur gaya bahsa yang digunakan pengarang dan berusaha mengkaji muatan makna yang 
terkandung dalam novel Sebuah Usaha Melupakan karya Boy Candra.

Dalam penelitian ini yang menjadi Objek utama yang akan dianalisis adalah gaya bahasa dalam naskah novel Sebuah Usaha Melupakan karya Boy Candra.

Adapun langkah-langkah yang dilakukan dalam menganalisis data sebagai berikut.

a. Setelah membaca novel, peneliti mengidentifikasi data mengenai gaya bahasa dan diberikan kode.

b. Klasifikasi data, yaitu mengklasifikasi atau mengelompokan data berdasarkan permasalahan dalam penelitian dalam hal ini adalah data mengenai gaya bahasa dalam novel Sebuah Usaha Melupakan karya Boy Candra.

c. Deskripsi data, yaitu memaparkan data mengenai gaya bahasa yang telah diklasifikasi atau dikelompokan dalam bentuk kebahasan.

d. Interpetasi data, yaitu proses penafsiran data menggunakan bahasa penelitian sendiri mengenai gaya bahasa dalam novel Sebuah Usaha Melupakan karya Boy Candra.

\section{HASIL DAN PEMBAHASAN}

Novel sebuah usaha melupakan karya Boy Candra menceritakan tentang seorang laki-laki yang sangat mencintai pasangannya, diawalnya dia memuji dan mengeluhkan pasangannya dengan kata-kata manis, pujian dan cinta, meski mereka berhubungan jarak jauh, hubungan mereka manis, penuh janji dan harapan. Namun ketika laki-laki dihianati oleh pasangannya akibat kehadiran orang ketiga, dia berubah menjadi pembenci, dan berkata kasar. Laki-laki yang tadinya sangat romantis, manis, dan penuh dengan kata-kata pujian tentang bagaimana bahagianya dia menemukan pasanganya, beralih mengeluarkan kata-kata yang kasar, dan kemudian bagaimana si laki-laki berjuang untuk menyembuhkan luka akibat perpisahan tersebut hingga dia dapat menyembuhkan luka dengan jatuh cinta kembali, menemukan cinta yang baru.

Sesuai dengan judul penelitian ini yaitu analisis Gaya bahasa dalam Novel Sebuah Usaha Melupakan karya Boy Candra, maka peneliti akan membahas gaya bahasa apa sajakah yang digunakan dalam novel ini. Penelitian ini dibatasi hanya pada dua kelompok gaya bahasa perbandingan dan gaya bahasa pertentangan. Adapun gaya bahasa perbandingan dan pertentangan yang terdapat dalam novel Sebuah Usaha Melupakan karya Boy Candra adalah sebagai berikut.

Berdasarkan analisis gaya bahasa perbandingan dalam novel Sebuah Usaha Melupakankarya Boy Candra, peneliti menemukan.

1. Gaya Bahasa Metafora

Gaya bahasa metafora adalah gaya bahasa yang membandingkan dua hal yang berbeda seolah dianggap sama. Penggambaran perbandingan tersebut dilukiskan secara implisit yaitu tanpa kata seperti, bak, ibarat, dan lain-lain sebagai penanda perbandingan diantara dua hal yang berbeda tersebut.

1) Semoga pedih dan segala hal yang butuh waktu pulih ini tidak menyerangmu suatu hari, kini aku sulit membedakan antara begitu cinta dan serangan rasa-rasa benci yang menghampiri, kamu sudah menjadi pisau yang menikam dadaku. Jika kelak kau punya waktu luang, kukirimkan kau sekotak kenang ( Boy Candra.2016:

Kutipan diatas termaksud gaya bahasa metafora karena membandingkan mantanya dengan pisau. pisau adalah bilah besi tipis dan tajam dan bertangkai sebagai alat 
pengiris. Dan disini tidak mungkin seseorang dapat berubah menjadi sebuah pisau.

2. Gaya Bahasa Personifikasi

Gaya bahasa personifikasi adalah gaya bahasa yang memberi sifat-sifat benda mati dengan sifat-sifat seperti yang dimiliki oleh manusia sehingga dapat bersifat dan bertingkahlaku sebagaimana halnya manusia.

1) Kita dua orang yang tak sehobi. Aku suka hal-hal yang sepi, tidak begitu suka keramaian. Jika pun ingin menikmati waktu denganmu, aku lebih suka menghabiskan waktu berdua saja. Menikmati angin yang bertiup lembut. Atau menatap senja diujung pantai yang tak begitu ramai (Boy Candra. 2016: 11).

Pada data tersebut yang menyatakan angin yang bertiup lembut mengandung gaya bahasa personifikasi. Jika kita baca sekilas maka kita tidak akan memahami apa yang ingin disampaikan oleh pengarang, maka dari itu kita dituntut untuk berimajinasi. Angin tidak memiki mulut untuk dapat bertiup lembut seperti manusia yang dapat meniup lembut menggunakan mulut.

3. Gaya Bahasa Dipersonifikasi

Gaya bahasa dipersonifikasi adalah kebalikan dari gaya bahasa personifikasi atau penginsanan kalau personifikasi menginsankan atau memanusiakan benda-benda, maka depersonifikasi justru membedakan manusia dengan insan. Biasanya gaya bahasa depersonifikasi ini terdapat dalam kalimat pengandaian yang secara eksplisit memanfaatkan kata kalau dan sejenisnya sebagai penjelas gagasan atau harapan.

1) Aku tetaplah lelaki biasa yang jatuh cinta kepadamu. Biarlah aku menjadi abu, kau tetap menjadi api berkali-kali membakar rinduku. Sekarat tetapi tidak pernah mati. Pergilah jika itu pilihan yang baik menurutmu, meski pada saat yang sama kau menghadapkan kenyataan pahit untuk hidupku (Boy Candra. 2016: 145).

Data diatas mengandung gaya bahasa dipersonifikasi. Karana menbandingkan dirinya seperti $a b u$ dan pasanganya seperti api. Abu adalah nama yang diberikan pada semua residu non cair yang tersisa setelah sempel dibakar dan sebagian besar terdiri dari oksida logam. Sementara api adalah oksida cepat terhadap material dalam proses pembakaran kimiawi, yang menghasilkan panas, cahaya dan berbagai hasil reaksi kimia lainnya.

4. Gaya bahasa antitesis

Gaya bahasa antitesis merupakan gaya bahasa yang mengadakan komperasi atau perbandingan dua antonim yaitu kata-kata yang mengandung ciri-ciri semantik yang bertentangan. Gaya bahasa antitesis mengandung antonim dalam suatu kalimat.

1) Aku berusaha memahami sifatmu yang masih asing untukku.begitupun kamu,yang dengan senang hati memerima duniaku. Hal yang barakali jarang atau belum pernah kamu temui sama sekali. Kita dua orang yang tak sehobi. Aku suka hal-hal yang sepi, tidak begitu suka keramaian. Jikapun ingin menikmati waktu denganmu, aku lebih suka menghabiskan waktu berdua saja (Boy Candra. 2016: 11).

Pada data diatas mengandung gaya bahasa antitesis. Kata sepi berlawanan dengan keramaian.

1. Gaya Bahasa Hiperbola

Gaya bahasa hiperbola adalah gaya bahasa yang mengandung pernyataan yang berlebih-lebihan dengan maksud memberi penekanan pada suatu pernyataan untuk meningkatkan kesan dan pengaruhnya.

1) Barangkali yang paling mungkin membunuh dua orang yang saling berhubungan jarak jauh adalah rasa curiga. 
Perasaan yang timbul di kepala, yang mengarah pada perusakan kepercayaan. Jika tidak bisa mengendalikan diri, ia bisa tumbuh menjadi api cemburu yang tak beralasan. Lalu pelan-pean membakar dua orang yang sedang berjuang bertahan. Perasaan curiga adalah bibit pembunuh yang paling berbahaya dan buta. Ia butuh dikendalikan dan ditenangkan. Lalu dibunuh pelan-pelan (Boy Candra. 2016: 31).

Bibit dalam arti umum adalah tanaman atau bagian dari tanaman yang digunakan untuk mengembang biakan tanaman tersebut dan tidak dapat membunuh seseorang, sementara curiga adalah perasaan yang timbul dihati manusia dan perasaan ini bersifat abstrak dan tidak dapat dilihat Cuma dapat dirasakan. dan Curiga dalam kutipan diatas hanya sebagai perumpaan yang dapat membunuh.

\section{Kesimpulan}

Berdasarkan penelitian yang dilakukan dapat disimpulkan bahwa gaya bahasa perbandingan yang terdapat pada novel sebuah usaha melupakan karya Boy Candra terdapat 4 jenis gaya bahasa yaitu:

Gaya bahasa metafora yang ditandai dengan penggunaan kata-kata perbandingan antara dua hal yang berbeda seolah dianggap sama. Penggambaran perbandingan tersebut dilukiskan secara impinsif yaitu tanpa kata seperti, bak, ibarat dan lain-lain sebagai penanda perbandigan.

Gaya bahasa personifikasi adalah gaya bahasa yang memberi sifat-sifat benda mati dengan sifat-sifat seperti yang dimiliki oleh manusia sehingga dapat bersifat dan bertingkahlaku sebagaimana halnya manusia.

Gaya bahasa dipersonifikasi adalah kebalikan dari gaya bahasa personifikasi atau penginsanan kalau personifikasi menginsankan atau memanusiakan benda-benda, maka depersonifikasi justru membedakan manusia dengan insan. Biasanya gaya bahasa depersonifikasi ini terdapat dalam kalimat pengandaian yang secara eksplisit memanfaatkan kata kalau dan sejenisnya sebagai penjelas gagasan atau harapan.

Gaya bahasa dipersonifikasi adalah kebalikan dari gaya bahasa personifikasi atau penginsanan kalau personifikasi menginsankan atau memanusiakan benda-benda, maka depersonifikasi justru membedakan manusia dengan insan. Biasanya gaya bahasa depersonifikasi ini terdapat dalam kalimat pengandaian yang secara eksplisit memanfaatkan kata kalau dan sejenisnya sebagai penjelas gagasan atau harapan.Gaya bahasa pertentangan pada novel sebuah usaha melupakan karya Boy Candra terdapat 1 jenis gaya bahasa yaitu:

Gaya bahasa hiperbola adalah gaya bahasa yang mengandung pernyataan yang berlebih-lebihan dengan maksud memberi penekanan pada suatu pernyataan untuk meningkatkan kesan dan pengaruhnya.

Berdasarkan hasil analisis sampai dengan rumusan kesimpulan diatas maka penulis menyampaikan beberapa hal.

a. Perlu adanya peningkatan dalam penelitian sastra pada umumnya dan penelitian pada novel khususnya.

b. Disarankan pada peneliti lain yang berminat mengkaji teks sastra, hendaknya diperhatikan bahwa hasil penelitianya harus mempunyai relevansi dengan pengajaran bahasa indonesia sehingga keberadaan penelitian yang dilakukan akan 
lebih bermanfaat selain itu, dapat dilakukan penelitian lebih lanjut terhadap novel Sebuah Usaha Melupakan baik dari segi gaya bahasa atau pun dari segi lainya karena penelitian ini masih banyak kekurangannya, masih banyak gaya bahasa yang belum diidentifikasi, dan analisis makna gaya bahasa yang belum tajam apabila dapat dilakukan penelitian lebih lanjut terhadap novel Sebuah Usaha Melupakan, diharapkan hasil penelitian dapat melengkapi kekurangan penelitian ini.

\section{DAFTAR PUSTAKA}

Badrun, Ahmad. 1983. Pengantar Ilmu Sastra (Teori Sastra). Surabaya: Usaha Nasional Indonesia.

Candra, Boy. 2016. Sebuah Usaha Melupakan. Jakarta: Mediakita.

Kusmawati. 2010. Analisis Pemakaian Gaya Bahasa Pada Iklan Produk Kecantikan Perawatan Kulit Wajah Di Televisi. Surakarta: Universitas Sebelas Maret.

Laila, Aruna. 2016. Gaya Bahasa Perbandingan Dalam Kumpulan Puisi Melihat Api Bekerja Karya M Aan Mansyur. Sumatra Barat: STKIP PGRI.

Nurgiyantoro, Burhan. 2010. Teori Pengkajian Fiksi. Yogyakarta: Gadjah Mada University Press.

Redaksi, PM. 2012. Sastra Indonesia Paling Lengkap. Depok- Jawa Barat: Pustaka Makmur.

Riswandi, Bode dan Kusmini, Titin. 2010. Pembelajaran Apresiasi Proa Fiksi. Tasikmalaya: Siklus Pustaka.

Tarigan, Henry Guntur, 1990. Pengajaran Gaya Bahasa. Bandung: Angkasa.

Wiyatmi. 2009. Pengantar Kajian Sastra. Yogyakarta:

Perpustakaan Nasional. 